\title{
85677 - PROJETO HOSPITALIDADE NÃO TEM IDADE - QUALIDADE NO ATENDIMENTO A IDOSOS E TURISTAS NO COMÉRCIO, SERVIÇOS E TURISMO
}

\author{
Pôster - Gerontologia
}

Gisele Martins da Cunha / da Cunha, G. M. / Prefeitura de Veranópolis; Ana Paula Soliman / Soliman, A.P. / DSC Consultoria em Serviços Turísticos Ltda; Diana Alessio Tomiello / Tomiello, D. A. / Prefeitura de Veranópolis; Cristiano Valduga Dal Pai / Dal Pai, C. V. / Prefeitura de Veranópolis; Antônio Henrique Chiaradia / Chiaradia, A. H. / Toni Formaiari Passeios Turísticos; Lilian Zieger / Zieger, L. / Serviços Educacionais Lilian Zieger e Equipe Ltda

Introdução: Em todo mundo as cidades estão crescendo e envelhecendo. No RS, conforme Censo de 2010, 13,6\% da população tem mais de 60 anos, sendo o Estado mais envelhecido do país. Estima-se que esta população, em 2060, corresponderá a 1/3 da população total no País. Para atender a grande expectativa deste público, os comerciantes e prestadores de serviços precisam preparar-se para este mercado. Veranópolis é reconhecida pela OMS desde 2016 como Cidade Amiga do Idoso, com o Projeto "Veranópolis: Cidade Para Todas as Idades". Ao integrar a rede global, foram criados projetos voltados ao envelhecimento populacional, como o Projeto de Qualidade no Atendimento a Idosos e Turistas -Hospitalidade Não Tem Idade. Objetivo: Qualificar empreendedores e seus estabelecimentos para melhor atender idosos e turistas, tornando o município uma cidade amigável ao idoso. Métodos: Desenvolvido pela Prefeitura, ACIV, Conselho Municipal do Idoso e consultoria externa, a dinâmica compreende palestras com os temas: atendimento a idosos, suas necessidades e limitações, tendências do mercado e oferta turística; visitas técnicas de avaliação dos empreendimentos; criação de materiais de apoio e material informativo para os idosos. Participam profissionais de diversas áreas, como geriatras, arquitetos, psicólogas, empreendedores e pedagogas. Resultados: Até o momento foram realizadas 2 edições, participaram 37 empreendedores somando 62 participantes, visitas técnicas e lançamento do livro "Em Veranópolis, Hospitalidade não tem idade!". Conclusões: O projeto possui grande importância para a melhora no atendimento adaptando suas estruturas e serviços para que sejam acessíveis e includentes às pessoas idosas de forma contínua e promovendo o município de Veranópolis como Terra da Longevidade.

Palavras-chave: Envelhecimento ativo, turismo e idosos.

Referências: ASSOCIAÇÃO VERANENSE DE ASSISTÊNCIA EM SAÚDE (AVAES) E CENTRO INTERNACIONAL DE LONGEVIDADE BRASIL (ILC-BRASIL). Veranópolis - Cidade Para Todas As Idades 'Envelhecimento Ativo: Criando um Município Para Todas As Idades'. Veranópolis: 2016. PROJEÇÃO DA POPULAÇÃO DO BRASIL POR SEXO E IDADE: 2000-2060. Disponível em <https://ww2.ibge.gov.br/home/estatistica/populacao/projecao_da_populacao/2013/default_tab. shtm > . Acesso em 02 de jun de 2016. WHO AGE-FRIENDLY CITIES PROJECT METHODOLOGY - VANCOUVER PROTOCOL. Disponível em < https://www.who.int/ageing/publications/Microsoft\%20Word\%20-\%20AFC_Vancouver_protocol.pdf>. Acesso em 02 de jun de 2016. 